\title{
WEATHER EFFECTS ON AUTUMN NOCTURNAL MIGRATION OF PASSERINES ON OPPOSITE SHORES OF THE ST. LAWRENCE ESTUARY
}

\author{
François Gagnon, 1,2,3,8 Jacques Ibarzabal, ${ }^{2,3}$ Jean-Pierre L. Savard, ${ }^{3,4}$ \\ Pierre Vaillancourt, ${ }^{5}$ Marc Bélisle, ${ }^{3,6}$ and Charles M. Francis ${ }^{7}$ \\ ${ }^{1}$ Canadian Wildlife Service, Environment Canada, 1141, route de l'Église, P.O. Box 10100, Québec, Québec, G1V 4H5, Canada; \\ ${ }^{2}$ Département des sciences fondamentales, Université du Québec à Chicoutimi, 555, Boulevard de l'Université, \\ Chicoutimi, Québec, G7H 2B1, Canada; \\ ${ }^{3}$ Observatoire d'oiseaux de Tadoussac, 302 de la Rivière, Les Bergeronnes, Québec, G1T 1G0, Canada; \\ ${ }^{4}$ Wildlife Research Division, Wildlife and Landscape Science Directorate, Science and Technology Branch, Environment Canada, \\ 1141 Route de l'Église, P.O. Box 10100, Québec, Québec, G1V 4H5, Canada; \\ ${ }^{5}$ Quebec Storm Prediction Centre, Meteorological Service of Canada, Environment Canada, Place Bonaventure, Portail Nord-Est, \\ Montréal, Québec, H5A 1L9, Canada; \\ ${ }^{6}$ Canadian Research Chair in Spatial and Landscape Ecology, Département de biologie, Université de Sherbrooke, \\ 2500 Boulevard de l'Université, Sherbrooke, Québec, J1K 2R1, Canada; and \\ ${ }^{7}$ Canadian Wildlife Service, Environment Canada, National Wildlife Research Centre, Ottawa, Ontario, K1A OH3, Canada
}

\begin{abstract}
AвSTRACT.-We modeled migration intensity as a function of weather, using nightly migration measurements from Doppler surveillance weather radar during autumn migration on the north (Côte-Nord) and south (Gaspésie) shores of the St. Lawrence estuary, Québec, Canada. The radar had negative elevation angles, an uncommon characteristic among weather radars, which allowed simultaneous low-altitude monitoring of bird migration on each side of the estuary. Precipitation and wind both had strong effects on the intensity of migration. Very few birds migrated when $>40 \%$ of the area had precipitation, especially when winds were strong. Light winds were associated with the strongest migration intensity, regardless of wind direction; in stronger winds, migration was likely only when winds were predominantly from the north. Days immediately after adverse weather events, which are assumed to lead to an accumulation of migrants, were associated with an increase in the intensity of migration in Côte-Nord, but not in Gaspésie. Time since the passage of a cold front had no effect in either region. Bird flight direction and behavior in relation to wind differed on each side of the estuary. On Côte-Nord, birds tended to migrate in a southwesterly direction along the St. Lawrence north coast, in a direction relatively unaffected by wind direction; they compensated or overcompensated for wind drift by following the coast. By contrast, birds in Gaspésie tended to fly in a more southerly direction. They migrated partially or almost fully downwind with only limited compensation, their flight direction often changing with wind direction. Received 31 August 2009, accepted 8 November 2010.
\end{abstract}

Key words: circular regression, migratory behavior, modeling, nocturnal migration, predictive models, songbird migration, weather radar, wind selectivity.

\section{Effets des conditions météorologiques sur la migration nocturne automnale des passereaux de chaque côté de l'estuaire du Saint-Laurent}

RÉSUMÉ.-Nous avons modélisé l'intensité migratoire automnale en fonction de la météo, en utilisant des mesures de la migration nocturne prises à la fois sur la rive nord (Côte-Nord) et la rive sud (Gaspésie) de l'estuaire du Saint-Laurent, Québec, Canada, à l'aide d'un radar Doppler de surveillance météorologique. Ce radar effectue des balayages à des angles négatifs, une caractéristique rare chez les radars météo qui permet entre autres, de relever des données de migration d'oiseaux à basse altitude et simultanément de chaque côté de l'estuaire. Nos résultats montrent que les précipitations et le vent avaient de forts effets sur l'intensité migratoire. Peu d'oiseaux migraient quand $40 \%$ ou plus du territoire était affecté par des précipitations, particulièrement en combinaison avec des vents forts. Les plus fortes intensités migratoires étaient associés avec des vents légers, peu importe la direction du vent; par vents forts, la migration était plus probable quand les vents avaient une composante nord. Un évènement de conditions météo adverses à la migration s'ensuivait d'une augmentation de l'intensité migratoire sur la Côte-Nord, mais pas en Gaspésie. Le passage d'un front

The Auk, Vol. 128, Number 1, pages 99-112. ISSN 0004-8038, electronic ISSN 1938-4254. @ 2011 by The American Ornithologists' Union. All rights reserved. Please direct all requests for permission to photocopy or reproduce article content through the University of California Press's Rights and Permissions website, http://www.ucpressjournals. com/reprintInfo.asp. DOI: 10.1525/auk.2011.09161 
froid n'avait aucun effet sur la migration dans l'une ou l'autre des deux régions. La direction de vol des oiseaux et leur comportement relativement au vent différaient de chaque côté de l'estuaire. Sur la Côte-Nord, les oiseaux avaient tendance à migrer vers le sud-ouest, le long de la rive nord du Saint-Laurent; cette direction de vol était peu affectée par la direction du vent et les oiseaux suivaient la côte en compensant ou surcompensant pour la dérive par les vents. En opposition, les oiseaux en Gaspésie avaient tendance à voler vers le sud; leur migration se faisait en suivant partiellement ou pleinement le vent avec peu de compensation et avec une direction de vol qui changeait souvent avec la direction du vent.

THE MAIN WEATHER factors known to influence daily departure decisions of nocturnal migratory birds are wind and precipitation (Richardson 1978, 1990; Åkesson and Hedenström 2000; Van Belle et al. 2007). Winds affect energetic needs during flight as well as the orientation of migration (Alerstam and Hedenström 1998, Weber et al. 1998, Liechti 2006). Light head winds or lightto-moderate tailwinds are often associated with large migration events (Alerstam 1978; Richardson 1978, 1990; Liechti 2006). However, flight strategies in relation to wind-in particular, departure decisions and compensation for wind drift-can vary among species or age classes (Thorup et al. 2003, 2007; Reilly and Reilly 2009) or with geography, including proximity to coastlines (Alerstam and Pettersson 1977, Bingman et al. 1982, Bruderer and Liechti 1998), and may be influenced by the previous days' weather (reviews by Richardson 1990, Liechti 2006). Precipitation can lead to partial reduction or total suppression of migration activity (Richardson 1978, Erni et al. 2002, Schaub et al. 2004), depending on its strength, amount, and duration (Van Belle et al. 2007). Extensive precipitation may lower the ability of birds to orient, and may increase drag and flight costs (Schaub et al. 2004). Consequently, adverse weather (strong head winds or heavy precipitation) may cause birds to delay departure and accumulate in staging areas (Alerstam and Hedenström 1998, Liechti 2006, Van Belle et al. 2007), which may lead to intensified migration on subsequent nights with good weather. Large movements of birds have also been linked to passage of a cold front, with birds departing in the evening after the front has passed (Richardson 1978). Associations of migration intensity with changes in atmospheric pressure, temperature, or relative humidity (Richardson 1978, Zehnder et al. 2001, Van Belle et al. 2007) may be due not to these factors themselves but to their correlation with wind speed and direction (Richardson 1978), which are believed to be the main factors influencing departure decisions of birds (Richardson 1990, Åkesson and Hedenström 2000, Liechti 2006).

The relationship between major topographical features, such as coastlines, and the effect of weather patterns on bird migration has been studied in a few areas (Alerstam and Pettersson 1977, Bingman et al. 1982, Bruderer and Liechti 1998) but might be expected to vary geographically-depending, for example, on the orientation of the coastline in relation to the migration direction, as well as the direction and intensity of prevailing winds. Understanding such relationships is important for predicting migration intensity. Effective forecasts of migration intensity, both in space and in time, can be valuable for many purposes, including assisting with environmental assessment, reducing the likelihood of bird collisions with tall structures, avoiding risks to human safety such as collisions with aircraft, and contributing to a better understanding of avian migration.

The St. Lawrence estuary in Quebec is oriented in a northeastsouthwest direction and can act as a leading line for migration. It is not an absolute barrier to bird migration, in that some nocturnal migrants fly across it, but the majority of birds migrate in parallel to the shoreline (Gagnon et al. 2011). This may be due to an aversion to cross this barrier, or it may be because birds select a different migration route. Many bird species are believed to use topographical features such as shore lines to compensate for wind drift (Alerstam and Pettersson 1977, Bingman et al. 1982, Åkesson 1993, Bruderer and Liechti 1998, Zehnder et al. 2001), but their tendency to do this may depend on their location in relation to the shoreline, as well as their intended migration direction. By contrast, in areas without marked topographic features, it is possible that birds are less able to compensate for wind drift, even if this leads to migration along routes that are unfavorable. For these reasons, we might expect the influence of weather-and particularly of wind direction-on the intensity and direction of autumn migration to differ between the north and south shores of the St. Lawrence.

Our objectives in the present study were threefold. First, we used a Canadian weather surveillance radar to estimate the influence of weather on the intensity of autumn nocturnal migration in passerines that migrated along the St. Lawrence. Second, we used graphic displays of first- and second-order circular functions (Anderson-Cook 2000) to visualize and model the influence of wind vector direction and speed as well as other weather variables on the intensity of migration to develop predictive models of migration intensity. Finally, we determined how and whether migration patterns, including intensity, direction and their relationships with wind, differed on both shores of the estuary.

\section{Methods}

Study area.-Migration data were collected on both sides of the St. Lawrence estuary using the Doppler weather surveillance radar at Val d'Irène (XAM). XAM is located at the base of the Gaspé Peninsula in Quebec $\left(49^{\circ} 28^{\prime} \mathrm{N}, 67^{\circ} 36^{\prime} \mathrm{W}\right), 40 \mathrm{~km}$ south of Matane (Fig. 1). The maximum scanning range is $256 \mathrm{~km}$, including the easternmost part of the St. Lawrence estuary and the westernmost part of the Gulf of St. Lawrence (Fig. 1). Within the area covered by the radar, the estuary's width ranges between 24 and $70 \mathrm{~km}$ and the coasts are oriented approximately northeast-southwest. We divided the study area into two regions: Côte-Nord on the north of the estuary and Gaspésie on the south (Fig. 1). We chose a boundary between these regions at one-quarter the width of the St. Lawrence from the south coast (minimum distance from XAM $=42 \mathrm{~km}$ ) on the basis of a preliminary examination of bird migration from a sample of nights. Both regions include land and sea areas, but on Côte-Nord most birds detected on the radar were over the estuary, particularly along the north coast and flying parallel to it, thus depicting behaviors of birds moving in coastal environments. By contrast, most observations in Gaspésie were of birds over land, 


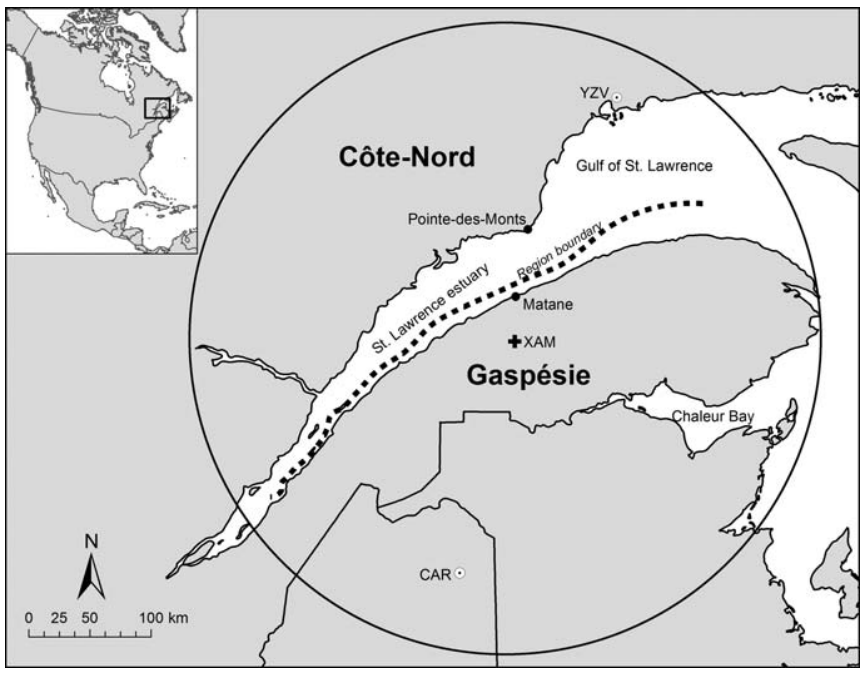

FIG. 1. Map of the study area. The circle approximates the $256-\mathrm{km}$ radius of the scanning range for the weather radar at Val d'Irène (XAM), Quebec. The dashed line indicates regional boundaries: Côte-Nord, north; Gaspésie, south, including northern New Brunswick and Maine. Sounding stations for the wind data are identified by their codes: Sept-îles, YZV Caribou, CAR.

depicting inland behaviors of birds that were flying away from the St. Lawrence.

Radar system.-XAM is a C-band Canadian weather surveillance radar (CWSR) characterized by a wave length of $5.32 \mathrm{~cm}$, a beam width of $0.65^{\circ}$, a peak power of $250 \mathrm{~kW}$, and a gain of $47.5 \mathrm{~dB}$ (Joe et al. 1998). A normalization of reflectivity with range $(R)$ of $1 / R^{2}$ is made by the radar processor to account for the decrease of reflectivity with range, assuming that targets fill the radar beam. The radar is located on a mountaintop (722 $\mathrm{m}$ above sea level [a.s.l.]), and its lowest elevation angle is at $-0.5^{\circ}$, which permits long-range scans at low altitude simultaneously on both sides of the estuary. A negative elevation angle is rare for weather radars; most radars scan at positive elevation angles above the horizon, which limits the detection of low-flying birds to shorter ranges (Gauthreaux et al. 2008). Like data from other CWSRs, data from XAM are collected at several angles over a 10-min period, with 5-min scans in conventional mode and 5-min scans in Doppler mode.

The conventional mode provides total reflectivity data over a $256-\mathrm{km}$ range for 24 elevation angles and has a pulse length of $2 \mu \mathrm{s}$ (Joe and Lapczak 2002). The reflectivity factor (hereafter "reflectivity") refers to the sum of the power back-scattered from individual targets to the radar antenna and depends on composition, size, and number of targets (Eastwood 1967, Rinehart 1997). Reflectivity during the nocturnal migration period was used as an index of bird density (believed to be mainly songbirds; Gagnon et al. 2010). The lowest end of the scale was set at the minimum (i.e., $-22 \mathrm{dBZ}$ ) to detect the relatively weak echoes of small numbers of songbirds during low-intensity migration nights. We used data from the five lowest elevation angles $\left(-0.5,-0.3,-0.1,0.1\right.$, and $\left.0.3^{\circ}\right)$ to obtain information on birds at various altitudes within the normal flight altitudes of passerines. The lower boundary of the lowest elevation angle reached sea level at a distance between $70 \mathrm{~km}$ and $175 \mathrm{~km}$ from the radar.

The Doppler mode provides radial velocity of targets (in $\mathrm{m} \mathrm{s}^{-1}$ ), It scans one elevation angle set at $-0.5^{\circ}$ with a $226-\mathrm{km}$ range and three elevation angles set at $-0.5,-0.2$, and $3.5^{\circ}$ with a $113-\mathrm{km}$ range. It has a pulse length of $0.8 \mu \mathrm{s}$ (for details, see Joe and Lapzak 2002). Radial velocity data were used to estimate flight directions of birds and also to estimate air speeds in the direction of travel to help discriminate birds from insects (see below).

We used the radar display software RAPID (developed at McGill University, Quebec), which processes raw digital radar data into products with a variety of scales, zoom features, elevation angle views, and animations for visualizing and analyzing the data (e.g., Fig. 2). Pixel resolution represents a surface area of $1 \mathrm{~km}^{2}$ for a range of 1-120 km, and $4 \mathrm{~km}^{2}$ for a range of $120-256 \mathrm{~km}$. An exact reflectivity value, azimuth, and distance from the radar can be obtained for each pixel.

Identification of bird echoes.-Two main criteria were used to identify birds on radar (Gauthreaux and Belser 1998, Koistinen 2000, Diehl et al. 2003): (1) appearance of a pulse of echoes on the radar at about one half-hour after sunset, corresponding with the usual takeoff time of nocturnally migrating passerines, and (2) a target airspeed $>7 \mathrm{~m} \mathrm{~s}^{-1}$, which helps in discriminating birds from insects (Larkin 1991). Dual-polarization capability on a radar can also help to differentiate birds from insects on the basis of shape (Gauthreaux et al 2008), but this feature was not available on the XAM radar. Airspeed of targets was calculated by subtracting the wind speed vector from the movement vectors of the targets. For this analysis, we estimated on each night the ground speed and direction of moving targets on the basis of the maximum observed radial velocity at 0000 hours UTC (Coordinated Universal Time: local time $=$ UTC -0400 hours). Wind components (i.e., speed and direction from origin) were taken at 0000 hours UTC from two sounding stations: Sept-Îles (YZV), located $214 \mathrm{~km}$ north of XAM, and Caribou (CAR), located $180 \mathrm{~km}$ south of XAM (Fig. 1; see Acknowledgments). These were selected as the most reliable stations for each shore on the basis of North American surface analysis charts at 1000 Mbar-0000 hours UTC. In situations where the estimates from one or both stations were rated with low reliability, we used the mean wind vector from both stations. Target vectors were compared with wind vectors at two elevations from among $300,600,900$, and $1,800 \mathrm{~m}$ a.s.l. that corresponded most closely with the particular Doppler elevation angle being analyzed.

Data used to test and describe migration patterns.-Radar data were collected over 95 nights (29 July-31 October 2003), but technical problems on four nights reduced our sample to 91 nights. Six of these nights were dominated by unknown targets that were likely insects and were considered nights with no migration. Even on nights with extensive precipitation, the intensity of bird migration could be estimated on the basis of areas within the radar range where there was no precipitation. For each night, we computed several variables, including a bird migration activity index, flight track direction, and predictor variables. We computed the bird migration activity index (BMA) from both the average reflectivity (on a linear scale) and the duration of peak activity. We examined radar displays at 10-min time intervals throughout the night to determine the extent and intensity of echoes that appeared to be 


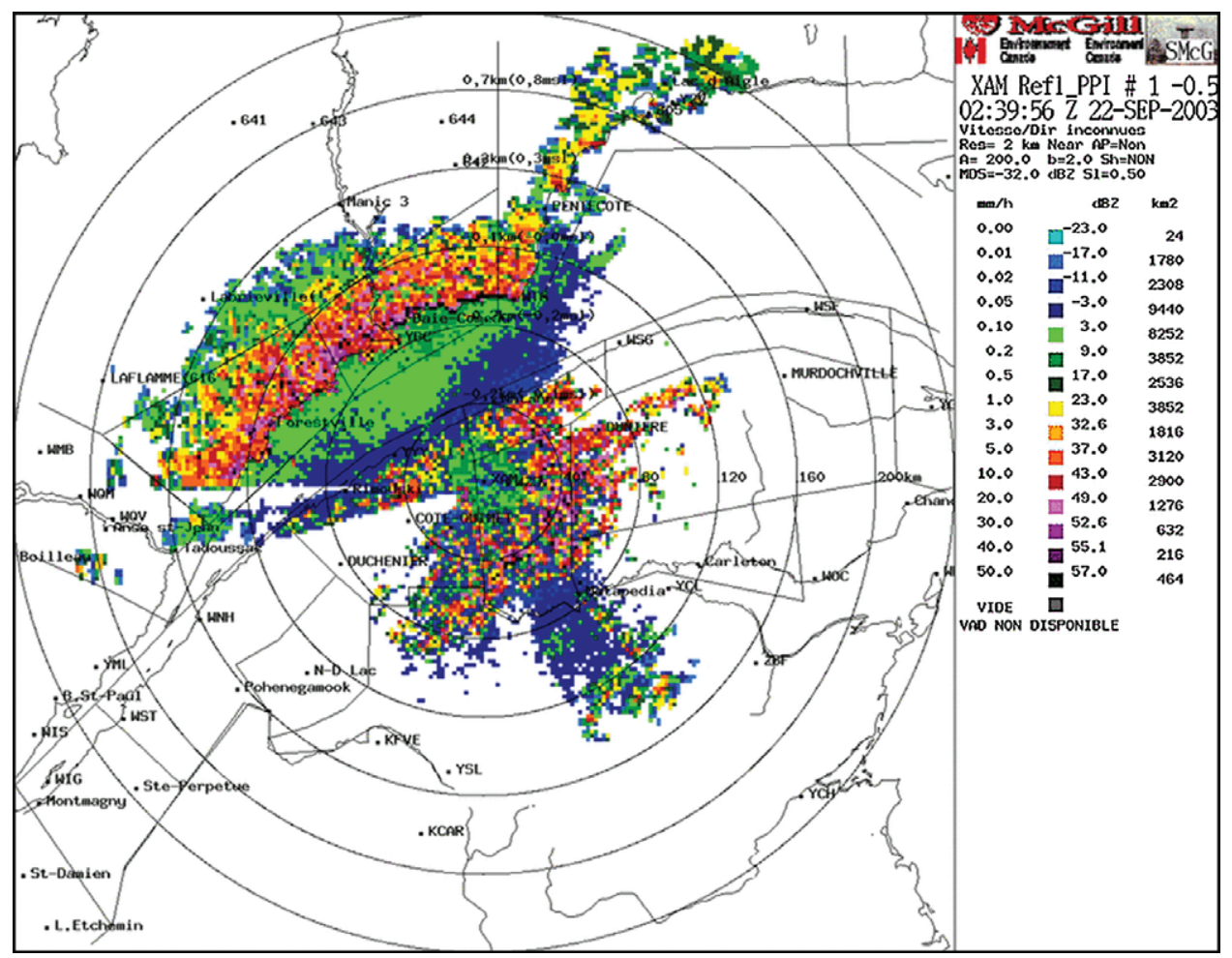

FIG. 2. Sample radar imagery of the Val d'Irène Canadian weather surveillance radar (XAM) during one night of heavy migration as displayed with the software RAPID. The legend appears on the right panel of the image. The image shows conventional mode reflectivity at the $240-\mathrm{km}$ range at the lowest elevation angle $\left(-0.5^{\circ}\right)$ on a night of heavy migration, 04:09 hours after sunset (0239 hours UTC, 22 September 2003). Range circles are 40 km apart, and the underlying contour map can be compared with Figure 1 to locate geographic features. On this image, warm-colored pixels represent strong echoes from ground clutter, whereas green and blue pixels represent weaker echoes, mainly from birds. These were identified by their appearance shortly after sunset, as well as their radial velocity as determined from the Doppler product (not shown).

birds. When peak activity was reached, we estimated the average reflectivity as the modal value (in $\mathrm{dBZ}$ ) for the area of bird echoes in each region. The duration of peak activity was defined as the period over which this modal value remained essentially unchanged. Reflectivity was sampled in all areas that were free of ground, sea, or rain echoes. This area varied with the elevation angle (there were more ground echoes at lower angles) and, in the case of sea or rain echoes, varied among nights, depending on weather. For this analysis, we used reflectivity values from the conventional mode rather than the Doppler mode because they were available at a much longer range. Modal reflectivity was transformed to linear reflectivity $Z$, where $Z=10^{\mathrm{dBZ} Z 110}$, which was then used to calculate the BMA index, defined as the sum of reflectivity values multiplied by their duration over the five elevation angles:

$$
\mathrm{BMA}=\sum_{\text {angle }=i}^{j} \mathrm{Z} * \text { duration }
$$

This index was computed separately for each region. We then transformed the BMA index into four migration intensity categories to be used as response variables in statistical analyses: strong, medium, weak, and no migration. Thresholds of BMA between the categories were selected to somewhat balance the number of nights in each category, and differed between regions because migration was often weaker in Gaspésie (Côte-Nord: strong $\geq 22$; medium $=$ $10-21.9$; weak $=0-9.9$; none $=0$; Gaspésie: strong $\geq 8.5$; medium $=$ $2.7-8.4$; weak $=2.7-8.3$; none $=0$ ).

Hereafter, "flight direction" refers to the bearing toward which birds were flying and "wind direction" refers to the direction from which the wind originated. The "direction of origin" of the birds was used for some analyses to match the definition of wind direction and represents the direction from which the birds were flying. Modal flight directions and speeds for all echoes in each region were estimated from the Doppler mode, twice per night, 90 min after sunset and at one-third of night length (to reflect the sampling time of wind data at the strongest moment of migration) at two elevation angles $\left(-0.5^{\circ}\right.$ and $\left.-0.2^{\circ}\right)$. These measurements reflect the dominant direction of the movement of birds at each time frame and angle in each region. These four measurements were averaged (using circular statistics) to produce a single flight direction for each region on each night. Sample sizes were smaller for flight direction data than for migration categories, especially at low migration intensities, because the Doppler mode radar has a shorter pulse length that limits its range, particularly with low target densities (Joe and Lapczak 2002). Hence, there were some nights when birds could be detected in the conventional mode but not the Doppler mode.

As an index of wind-drift compensation by birds, we computed the smallest absolute value $\beta$ of the difference in angle 
between the direction of origin of the birds and the wind direction, where $0^{\circ}$ is a tailwind, $180^{\circ}$ a head wind, and $90^{\circ}$ a cross wind from either the left or right side.

The predictor variables that we focused on for our analyses were precipitation and wind, the two variables that have previously been shown to be most relevant for predicting migration behavior (see above). The proportion of precipitation coverage in each region (\%) was taken from the XAM product referred to as "CAPPI 1.5 km" (Constant Altitude Plan Position Indicator at $1.5 \mathrm{~km}$ a.s.l.), which shows precipitation over the entire radar range. Coverage was estimated to the nearest $10 \%(0=0-9 \%, 10=10-19 \%$, etc. $)$ 40 min after sunset, which is around the mean time that birds begin nightly flights (Gagnon et al. 2011).

Wind components were speed $\left(\mathrm{m} \mathrm{s}^{-1}\right)$ and direction (in degrees, where north $=0^{\circ}$ ) taken at 0000 hours UTC from sounding stations (see above). For each region, wind was selected from the sounding station that had the greatest reliability given the synoptic situation on North American surface analysis charts at 1000 Mbar-0000 hours UTC. In ambiguous situations in which neither station was completely reliable, the mean wind vector from both sounding stations was used.

Wind data were taken at the nearest altitude corresponding to half the nightly highest altitude of flight. The latter corresponded to the mean upper boundary altitude of the three highest elevation angles (of the five we analyzed) at which migration was detected in each region in our analyses. Upper boundaries were computed using the beam height equation from Rinehart (1997) for the average range of bird detections during peak activity estimated on each night for each conventional elevation angle in each region. For nights without migration, wind at the nearest available altitude to $600 \mathrm{~m}$ a.s.l. was used, because that was the most frequently used altitude by birds in both regions during the study period (F. Gagnon unpubl. data).

Two circular regression functions were used to model the effect of wind. (1) The first-order circular wind function has two parameters and models the response variable as a tilted disk with a single symmetric maximum and minimum. (2) The second-order circular wind function has four parameters, which accentuates the additive nature of the model and provides additional curvature by allowing up to two, potentially asymmetric, maxima and minima (Anderson-Cook 2000). Because wind is a vector that has both an inherent direction ( $\theta$ in radians) and a length (speed $[v]$ in $\mathrm{m} \mathrm{s}^{-1}$ ) component, we always expressed it as an interaction factor. The first-order wind function was calculated as

$$
\sin (\theta) * \mathrm{v}+\cos (\theta) * v
$$

whereas the second-order wind function was calculated as

$$
\sin (2 \theta) * v+\cos (2 \theta) * v+[0.5-0.5 \cos (\theta)] * v+[0.5+0.5 \cos (\theta)] * v
$$

We included three additional predictor variables in the analyses. Date were transformed to a numerical variable from 29 July $(=1)$ until 31 October $(=95)$, and then entered into a secondorder polynomial orthogonal function to model the bell-shaped progression of bird migration activity during the whole season (Gagnon et al. 2011).

An adverse weather event was defined as a night with unfavorable weather for migration (i.e., extensive rain or strong head winds) that has the potential to delay departure and create an accumulation of birds ready to take off (Liechti 2006). We analyzed the relationship between the number of nights since the last adverse weather event in each region and bird migration. An adverse weather event was defined as precipitation coverage $\geq 40 \%$ or a head wind $\left(135-270^{\circ}\right)$ with speeds $\geq 11 \mathrm{~m} \mathrm{~s}^{-1}$ at 0000 hours UTC at the closest altitude to $300 \mathrm{~m}$ a.s.l. at sounding stations. The choice of a threshold for the precipitation coverage came from a graphic exploration of the average BMA in relation to precipitation within our data: BMA in each region drops to near zero at precipitation classes of $40 \%$ and $30 \%$ for Côte-Nord and Gaspésie, respectively. The head-wind speed threshold was selected on the basis of published values of flight speeds of passerines (Larkin 1991, Bruderer and Boldt 2001). Unfavorable wind directions were determined by examining the relationship between migration intensity and wind direction in our data (which were similar to those in the literature for other areas of eastern North America; e.g., Lowery and Newman 1966; Richardson 1972, 1978; Gauthreaux et al. 2003).

Cold fronts were also analyzed, because ornithologists often link strong migration events to passage of a cold front. We analyzed the effect of the number of nights since the last cold front passage at the Sept-Iles weather station (YZV) at sunset, using the same predictor variable for both regions. Cold-front passages were identified from surface analyses, using front charts provided by the Meteorological Service of Canada.

Statistics.-Our directional data analysis used circular statistical methods (Batschelet 1981, Fisher 1993, Jammalamadaka and SenGupta 2001) to analyze relationships among flight direction, flight intensity, and predictor variables. The dispersion parameter $\bar{r}$ indicates the scatter in directions about a circular mean, where $\bar{r}=1$, the maximum value, indicates that all directions are aligned to the mean (i.e., zero variance). The Rayleigh test of uniformity was used to test whether the hypothesis of random (uniform) dispersion of directions around the compass could be rejected in favor of a "preferred" direction. Confidence intervals around circular means (which may be asymmetrical) were calculated using maximum-likelihood estimates of a von Mises distribution fitted to parameters of each data set using 3,000 bootstrap samples. To evaluate whether mean directions differed between regions for identical periods, we used Rao's test of homogeneity (Jammalamadaka and SenGupta 2001) on data collected on the same nights.

Circular correlation (Fisher and Lee 1983) was used to test for relationships between bird flight direction and wind direction, and whether they differed between regions. This was done before calculating the wind drift parameter $(\beta)$, which for better understanding was reported on the half circle from $0^{\circ}$ (tailwind) to $180^{\circ}$ (head wind). Distributions of observed $\beta$ values were generally skewed, so we used the median rather than the mean as a central-tendency parameter and generated confidence intervals on the median using the percentile method on 1,000 nonparametric bootstrap replicates (Davison and Hinkley 1997, Carpenter and Bithell 2000). We also examined whether counts of side winds were predominantly from the left or right side of the $\beta$ values for each migration category using two-sided binomial exact tests (Zar 1996).

We analyzed most data using proportional-odds models, which are cumulative logistic regressions for ordered categorical data (Agresti 1996). These were preferred over models that treated BMA as a continuous response variable, because the continuous BMA index 
followed a gamma distribution with outliers that could not justifiably be removed. We followed Fox's (2003) recommendation for interpreting the effects of a chosen predictor variable by using a graphic display while controlling for other variables. This is easier to understand than the coefficients themselves in the presence of interactions.

Our candidate models included two sets of 11 models that we ran separately for each region. All models included date (as a second-order term). Precipitation was included in all models except the base model (model 1). The models included various combinations of days since an adverse weather event, days since the last cold front, a first-order circular wind function, or a second-order circular wind function. To limit the number of models, we restricted the set to a maximum of two of these three variables within the same model.

We used Akaike's information criterion corrected for small sample sizes (AIC ; Burnham and Anderson 2002) to rank and compare models. We used Akaike weights $\left(w_{i}\right)$ to assess the strength of evidence in support of each model. To assess the importance of each explanatory variable for explaining migration intensity and to generate predictive models, we performed model averaging (Burnham and Anderson 2002). Model-averaged coefficients are reported with their unconditional standard error and $95 \%$ confidence intervals (CI). All statistics were performed in the R statistical environment (R Development Core Team 2006).

\section{Results}

Weather.-During the study period, from 29 July to 31 October $2003,63 \%$ of nights were precipitation-free or nearly so in both regions $(0-10 \%$ precipitation coverage), and $14 \%$ were strongly affected by precipitation (50-100\%; Table 1A). Wind direction was related to precipitation coverage, being predominantly westerly to northwesterly during periods with little precipitation and predominantly easterly to southwesterly during high precipitation coverage (Table 1A). In both regions, westerly winds predominated and winds from the northeast were the least frequent (Table 1B). Wind speed varied with wind direction, but winds $>18 \mathrm{~m} \mathrm{~s}^{-1}$ were infrequent. On the first night after an adverse weather event, winds usually blew from the west (ranging between southwest and northwest). On the first night after passage of a cold front ( $<1$ day), winds were predominantly south to west (Table 1C).

TABLE 1. Summary of weather conditions from 29 July to 31 October 2003 ( $n=91$ nights) on the north (Côte-Nord) and south (Gaspésie) shores of the St. Lawrence estuary. Precipitation coverage was the proportion of a region covered by precipitation as seen on the XAM radar product CAPPI $1.5 \mathrm{~km}$, $40 \mathrm{~min}$ after sunset. Wind direction $\left(0^{\circ}=\right.$ north) and speed were taken from sounding-station data at 0000 hours UTC (see text). The dispersion parameter $r$ measures the strength of the consistency of the wind direction, with 0 representing complete dispersion and 1 indicating perfect directionality.

(A) Mean wind direction on nights with different levels of precipitation coverage

Precipitation coverage $(\%)$

\begin{tabular}{|c|c|c|c|c|c|c|c|}
\hline Région & Statistics & 0 & 10 & 20 & $30-40$ & $50-70$ & $80-100$ \\
\hline \multirow[t]{3}{*}{ Côte-Nord } & Number of nights & 35 & 25 & 10 & 11 & 6 & 7 \\
\hline & Mean wind direction $\left(^{\circ}\right)$ & 302 & 288 & 263 & 208 & 174 & 120 \\
\hline & $\bar{r}$ & 0.56 & 0.57 & 0.72 & 0.46 & 0.75 & 0.66 \\
\hline \multirow[t]{3}{*}{ Gaspésie } & Number of nights & 48 & 15 & 8 & 7 & 9 & 4 \\
\hline & Mean wind direction $\left(^{\circ}\right)$ & 283 & 274 & 296 & 172 & 186 & 89 \\
\hline & $\bar{r}$ & 0.5 & 0.62 & 0.63 & 0.67 & 0.39 & 0.75 \\
\hline
\end{tabular}

(B) Number of nights with different wind speed and direction

Wind direction

\begin{tabular}{|c|c|c|c|c|c|c|c|c|c|}
\hline \multirow[b]{2}{*}{ Region } & \multirow[b]{2}{*}{ Wind speed } & \\
\hline & & $\mathrm{N}$ & NE & $E$ & SE & $\mathrm{S}$ & SW & W & NW \\
\hline \multirow[t]{5}{*}{ Côte-Nord } & $0-6 \mathrm{~m} \mathrm{~s}^{-1}$ & 2 & 1 & 1 & 1 & 6 & 4 & 6 & 5 \\
\hline & $6-12 \mathrm{~m} \mathrm{~s}^{-1}$ & 4 & 1 & 3 & 6 & 0 & 7 & 9 & 9 \\
\hline & $12-18 \mathrm{~m} \mathrm{~s}^{-1}$ & 2 & 0 & 1 & 1 & 2 & 3 & 5 & 7 \\
\hline & $>18 \mathrm{~m} \mathrm{~s}^{-1}$ & 0 & 0 & 1 & 1 & 0 & 0 & 2 & 1 \\
\hline & Total & 8 & 2 & 6 & 9 & 8 & 14 & 22 & 22 \\
\hline \multirow[t]{5}{*}{ Gaspésie } & $0-6 \mathrm{~m} \mathrm{~s}^{-1}$ & 2 & 0 & 2 & 1 & 5 & 6 & 5 & 5 \\
\hline & $6-12 \mathrm{~m} \mathrm{~s}^{-1}$ & 5 & 1 & 3 & 5 & 0 & 7 & 10 & 7 \\
\hline & $12-18 \mathrm{~m} \mathrm{~s}^{-1}$ & 2 & 0 & 1 & 2 & 2 & 3 & 6 & 7 \\
\hline & $>18 \mathrm{~m} \mathrm{~s}^{-1}$ & 0 & 0 & 1 & 1 & 0 & 0 & 1 & 1 \\
\hline & Total & 9 & 1 & 7 & 9 & 7 & 16 & 22 & 20 \\
\hline
\end{tabular}

(C) Number of occurrence of each wind direction on the night following an adverse weather event or a cold front

\begin{tabular}{|c|c|c|c|c|c|c|c|c|c|c|}
\hline \multirow[b]{2}{*}{ Type of event } & \multirow[b]{2}{*}{ Région } & \multirow{2}{*}{$\begin{array}{c}\text { Total } \\
\text { occurrence }\end{array}$} & \multicolumn{8}{|c|}{ Wind direction } \\
\hline & & & $\mathrm{N}$ & $\mathrm{NE}$ & E & SE & $S$ & SW & W & NW \\
\hline \multirow[t]{2}{*}{ Adverse weather } & Côte-Nord & 17 & 1 & 0 & 0 & 1 & 1 & 3 & 5 & 6 \\
\hline & Gaspésie & 17 & 0 & 0 & 1 & 1 & 0 & 4 & 4 & 7 \\
\hline Cold front & Both regions & 19 & 1 & 1 & 2 & 3 & 4 & 3 & 5 & 0 \\
\hline
\end{tabular}


TABLE 2. Summary of the number of nights with different levels of migration on Côte-Nord and Gaspésie between 29 July and 31 October 2003 as measured on XAM weather radar, and the relation between the intensity of migration and the mean flight directions measured during the first half of the night, giving the dispersion parameter $(\bar{r}$, a measure of the consistency among nights in flight direction), the significance of a Rayleigh test for uniformity of flight direction $(P)$, and the $95 \%$ confidence intervals on the mean direction (requires a significant Rayleigh test).

\begin{tabular}{|c|c|c|c|c|c|c|}
\hline \multirow{2}{*}{$\begin{array}{l}\text { Migration } \\
\text { intensity } \\
\text { Category }\end{array}$} & \multirow[b]{2}{*}{$n^{\mathrm{a}}$} & \multicolumn{5}{|c|}{ Flight direction } \\
\hline & & $\begin{array}{c}\text { Mean } \\
\text { direction }\left(^{\circ}\right)\end{array}$ & $n^{\mathrm{b}}$ & $\bar{r}$ & $P$ & $95 \% \mathrm{Cl}\left({ }^{\circ}\right)$ \\
\hline \multicolumn{7}{|c|}{ (A) Côte-Nord } \\
\hline Strong & 17 & 221 & 17 & 0.92 & $<0.001$ & $209-231$ \\
\hline Medium & 19 & 246 & 16 & 0.98 & $<0.001$ & $240-253$ \\
\hline Weak & 19 & 207 & 6 & 0.74 & 0.030 & $170-240$ \\
\hline None & 36 & & & & & \\
\hline \multicolumn{7}{|c|}{ (B) Gaspésie } \\
\hline Strong & 14 & 187 & 14 & 0.87 & $<0.001$ & $172-204$ \\
\hline Medium & 27 & 161 & 25 & 0.47 & 0.003 & 129-196 \\
\hline Weak & 32 & 96 & 29 & 0.26 & 0.141 & NA \\
\hline None & 18 & & & & & \\
\hline
\end{tabular}

${ }^{a}$ Number of nights with each level of migration intensity.

b Number of nights that flight direction could be measured from the Doppler radar.

Migration.-Bird migration activity was detected on 55 nights in Côte-Nord and 73 in Gaspésie. The greater number of nights with no migration in Côte-Nord may have been partly related to its greater distance from the radar, and partly to the lower probability of detecting small numbers of targets at greater ranges from the radar (Rinehart 1997)

Mean flight directions differed between regions on nights when migration was detected in both areas (Rao's test of angular homogeneity for equality of mean: test $=21.86, \mathrm{df}=1, P<0.001, n=$ 39). Mean flight directions over Côte-Nord were southwest and westsouthwest for strong and medium migration, respectively, and had low dispersion around the mean ( $\bar{r}$ values near 1$)$, which indicates that they were similar on most nights (Table 2A); during weak migration, the mean directions were south-southwest with slightly higher dispersion. In Gaspésie, flight directions were to the south during strong migration and south-southeast during medium migration (Table 2B); during weak migration, flights did not show consistent directions.

Relation between flight and wind directions.-Within each category of migration intensity, we found no significant correlation between flight and wind directions over Côte-Nord (Table 3A). Median observed $\beta$ values indicated that, on average, birds were flying with winds nearly at right angles to their direction of flight during heavy migration, most frequently from the right side (west-northwest to north), primarily reflecting the dominant wind directions. In Gaspésie, there was a strong positive correlation between flight origin and wind directions during weak migration $(P=0.003)$, a weaker and marginally nonsignificant correlation $(P=0.06)$ during nights of medium migration, and no correlation during nights of strong migration (Table 3B). Median observed $\beta$ values suggested that birds were most likely to be flying with right-side-tailwinds (northwest to north) during strong migration, and with following winds from any side during medium and weak migrations.
TABLE 3. Relationships between bird origin (flight directions $-180^{\circ}$ ) and wind direction on Côte-Nord and Gaspésie for each category of migration intensity. The left side of the table presents results of circular correlations $(r, Z$-test, $P$ ) between bird origin and wind directions (sample sizes match the Doppler sample sizes in Table 1) over a complete compass. The right side of the table presents median observed $\beta$ (angle between bird origin and wind direction reported on a half-circle from $0^{\circ}$ [tailwind] to $180^{\circ}$ [head wind]) with confidence intervals of medians computed using 1,000 bootstrap replicates. Counts of nights with left or right side winds in relation to bird directions were tested for the possibility of equality using binomial exact tests $(P)$.

\begin{tabular}{|c|c|c|c|c|c|c|c|c|}
\hline \multirow[b]{3}{*}{ Category } & & & & \multicolumn{5}{|c|}{ Observed $\beta$} \\
\hline & \multicolumn{3}{|c|}{ Correlation } & \multirow{2}{*}{$\begin{array}{c}\text { Median } \\
\left({ }^{\circ}\right)\end{array}$} & \multirow{2}{*}{$\begin{array}{c}95 \% \mathrm{Cl} \\
\left(^{\circ}\right)\end{array}$} & \multicolumn{3}{|c|}{ Side of wind } \\
\hline & $\bar{r}$ & $Z$ & $P$ & & & Left & Right & $P$ \\
\hline \multicolumn{9}{|c|}{ (A) Côte-Nord } \\
\hline Strong & -0.32 & -1.67 & 0.095 & 79 & $61-120$ & 4 & 13 & 0.049 \\
\hline Medium & 0.31 & 1.358 & 0.175 & 144 & 123-152 & 2 & 14 & 0.004 \\
\hline Weak & 0.43 & 1.099 & 0.272 & 49 & 7-118 & 3 & 3 & 1.000 \\
\hline \multicolumn{9}{|c|}{ (B) Gaspésie } \\
\hline Strong & -0.14 & -0.452 & 0.652 & 44 & $34-73$ & 1 & 13 & 0.002 \\
\hline Medium & 0.40 & 1.869 & 0.062 & 27 & $9-37$ & 10 & 15 & 0.424 \\
\hline Weak & 0.57 & 3.001 & 0.003 & 29 & $17-35$ & 12 & 17 & 0.458 \\
\hline
\end{tabular}

In Gaspésie, when birds were flying in inappropriate directions (northerly or easterly, $0-135^{\circ}$ and $270-360^{\circ}$ ), which happened on some nights with medium and low migration intensities, the wind was typically blowing from the west or southwest with a mean direction of $252^{\circ}\left(\bar{r}=0.64, P<0.001,95 \% \mathrm{CI}: 232-269^{\circ}, n=33\right)$.

If we consider only nights when the wind had a northerly component (combining all wind strengths and migration categories), the mean direction of bird migration was $225^{\circ}(\bar{r}=0.85, P<$ $0.001,95 \%$ CI: $\left.212-236^{\circ}, n=27\right)$ on Côte-Nord and $166^{\circ}(\bar{r}=0.70$, $P<0.001,95 \%$ CI: $\left.151-185^{\circ}, n=36\right)$ in Gaspésie. When the wind had a southerly component, the mean direction on Côte-Nord was fairly similar $\left(240^{\circ} ; \bar{r}=0.99, P<0.001,95 \%\right.$ CI: $\left.237-244^{\circ} ; n=11\right)$, but there was a widely scattered nonsignificant mean direction of $81^{\circ}(\bar{r}=0.12, P<0.63, n=32)$ in Gaspésie.

Modeling migration: Model selection.-For Côte-Nord, the most parsimonious model included date, precipitation, a second-order wind function, and time since the most recent adverse weather event (Table 4A). For Gaspésie, models that included date, weather, and either a first- or second-order wind function received very similar support (Table $4 \mathrm{~B}$ ). Because several variations on these models also received some support, we used model averaging to derive predictive equations incorporating each of the parameters of interest (Table 5). Within these functions, date, precipitation coverage, and wind (first- and second-order wind functions) had coefficients with $95 \%$ CIs that did not overlap zero. The direction and effect of these parameters are described below and illustrated in Figures 3-6.

Date.-At Côte-Nord, the probability of strong migration peaked between mid-September and mid-October (Fig. 3). Under favorable weather conditions, the probability of strong migration was $\sim 80 \%$ in late September (Fig. 3A). Moderate migration was most likely early in the season under favorable weather 
TABLE 4. Comparison of proportional-odds logit models predicting nocturnal migration intensity during autumn 2003 on Côte-Nord and Gaspésie,

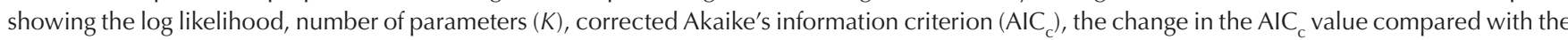
best model $\left(\triangle \mathrm{AIC} \mathrm{C}^{\prime}\right.$, where models with $\Delta \mathrm{AIC}_{\mathrm{c}}<2$ are in bold $)$, and the Akaike weights $\left(w_{i}\right)$. Variables: wind $1=$ first-order wind function and wind $2=$ second-order wind function.

\begin{tabular}{|c|c|c|c|c|c|c|}
\hline ID & Model & Log likelihood & $K$ & $\mathrm{AlC}_{\mathrm{C}}$ & $\Delta \mathrm{AIC}_{\mathrm{c}}$ & $w_{i}$ \\
\hline \multicolumn{7}{|c|}{ (A) Côte-Nord } \\
\hline 1 & date & -118.156 & 5 & 247.019 & 35.175 & 0.000 \\
\hline 2 & date+precip & -101.148 & 6 & 215.297 & 3.453 & 0.050 \\
\hline 3 & date+precip+adverse & -99.081 & 7 & 213.511 & 1.667 & 0.123 \\
\hline 4 & date+precip +coldfront & -101.111 & 7 & 217.571 & 5.727 & 0.016 \\
\hline 5 & date+precip+adverse+coldfront & -99.061 & 8 & 215.878 & 4.034 & 0.038 \\
\hline 6 & date+precip+wind 1 & -98.132 & 8 & 214.02 & 2.176 & 0.095 \\
\hline 7 & date + precip + wind $1+$ adverse & -96.676 & 9 & 213.574 & 1.730 & 0.119 \\
\hline 8 & date+precip+wind $1+$ coldfront & -98.055 & 9 & 216.332 & 4.488 & 0.030 \\
\hline 9 & date+precip+wind 2 & -94.941 & 10 & 212.631 & 0.787 & 0.191 \\
\hline 10 & date + precip + wind $2+$ adverse & -93.251 & 11 & 211.844 & 0.000 & 0.283 \\
\hline 11 & date+precip+wind $2+$ coldfront & -94.915 & 11 & 215.173 & 3.329 & 0.054 \\
\hline \multicolumn{7}{|c|}{ (B) Gaspésie } \\
\hline 1 & date & -118.156 & 5 & 247.019 & 22.468 & 0.000 \\
\hline 2 & date+precip & -107.307 & 6 & 227.614 & 3.063 & 0.057 \\
\hline 3 & date+precip+adverse & -106.847 & 7 & 229.042 & 4.491 & 0.028 \\
\hline 4 & date+precip+coldfront & -107.3 & 7 & 229.95 & 5.399 & 0.018 \\
\hline 5 & date+precip + adverse+coldfront & -106.753 & 8 & 231.262 & 6.711 & 0.009 \\
\hline 6 & date + precip+wind 1 & -103.397 & 8 & 224.551 & 0.000 & 0.265 \\
\hline 7 & date+precip + wind $1+$ adverse & -102.963 & 9 & 226.148 & 1.597 & 0.119 \\
\hline 8 & date+precip +wind $1+$ coldfront & -103.337 & 9 & 226.896 & 2.345 & 0.082 \\
\hline 9 & date+precip +wind 2 & -100.93 & 10 & 224.611 & 0.060 & 0.257 \\
\hline 10 & date+precip+wind $2+$ adverse & -100.684 & 11 & 226.711 & 2.160 & 0.090 \\
\hline 11 & date+precip + wind $2+$ coldfront & -100.862 & 11 & 227.065 & 2.514 & 0.075 \\
\hline
\end{tabular}

TABLE 5. Model-averaged estimates of coefficients, variance, and 95\% confidence intervals for all parameters included in candidate models for CôteNord and Gaspésie. Parameters in bold have strong evidence for an effect, because zero is excluded from the $95 \%$ confidence interval (Cl). For higherorder variables (i.e., date and wind), if any term has confidence intervals that exclude zero, the entire variable should be considered to have strong evidence for an effect on migration. Parameters in italics indicate variables in which zero is marginally included within the $95 \% \mathrm{Cl}$.

\begin{tabular}{|c|c|c|c|c|c|}
\hline Variable & Parameter $^{\mathrm{a}}$ & Coefficient & Variance & \multicolumn{2}{|c|}{$95 \% \mathrm{Cl}$} \\
\hline \multicolumn{6}{|l|}{ (A) Côte-Nord } \\
\hline \multirow[t]{2}{*}{ Date } & Polynomial, first order & 4.933 & 2.413 & 0.204 & 9.661 \\
\hline & Polynomial, second order & -4.605 & 2.399 & -9.308 & 0.098 \\
\hline Precipitation & Coverage (\%) & -0.629 & 0.164 & -0.951 & -0.307 \\
\hline Adverse weather event & Days since last event & -0.141 & 0.078 & -0.295 & 0.012 \\
\hline Cold front & Days since last front & -0.002 & 0.085 & -0.168 & 0.164 \\
\hline \multirow[t]{2}{*}{ Wind, first order } & $\sin (\theta) \bullet v^{\mathrm{a}}$ & 0.050 & 0.036 & -0.021 & 0.121 \\
\hline & $\cos (\theta) \bullet v$ & 0.079 & 0.040 & 0.001 & 0.158 \\
\hline \multirow[t]{4}{*}{ Wind, second order } & $\sin (2 \theta) \bullet v$ & -0.028 & 0.040 & -0.106 & 0.051 \\
\hline & $\cos (2 \theta) \bullet v$ & -0.004 & 0.042 & -0.087 & 0.078 \\
\hline & $0.5-0.5 \cos (2 \theta) \bullet v$ & -0.253 & 0.096 & -0.441 & -0.064 \\
\hline & $0.5+0.5 \cos (2 \theta) \bullet v$ & -0.080 & 0.072 & -0.221 & 0.061 \\
\hline \multicolumn{6}{|l|}{ (B) Gaspésie } \\
\hline \multirow[t]{2}{*}{ Date } & Polynomial, first order & 0.374 & 2.090 & -3.722 & 4.471 \\
\hline & Polynomial, second order & -5.916 & 2.248 & -10.323 & -1.509 \\
\hline Precipitation & Coverage $(\%)$ & -0.320 & 0.114 & -0.544 & -0.097 \\
\hline Adverse weather event & Days since last event & -0.052 & 0.061 & -0.172 & 0.068 \\
\hline Cold front & Days since last front & -0.026 & 0.076 & -0.174 & 0.123 \\
\hline \multirow[t]{2}{*}{ Wind, first order } & $\sin (\theta) \bullet v$ & -0.007 & 0.032 & -0.070 & 0.056 \\
\hline & $\cos (\theta) \bullet v$ & 0.092 & 0.035 & 0.024 & 0.160 \\
\hline \multirow[t]{4}{*}{ Wind, second order } & $\sin (2 \theta) \bullet v$ & 0.002 & 0.033 & -0.063 & 0.067 \\
\hline & $\cos (2 \theta) \bullet v$ & 0.004 & 0.034 & -0.062 & 0.070 \\
\hline & $0.5-0.5 \cos (2 \theta) \bullet v$ & -0.211 & 0.070 & -0.349 & -0.073 \\
\hline & $0.5+0.5 \cos (2 \theta) \bullet v$ & -0.006 & 0.065 & -0.133 & 0.120 \\
\hline
\end{tabular}

${ }^{\mathrm{a}} \theta=$ wind direction, $v=$ wind speed. 

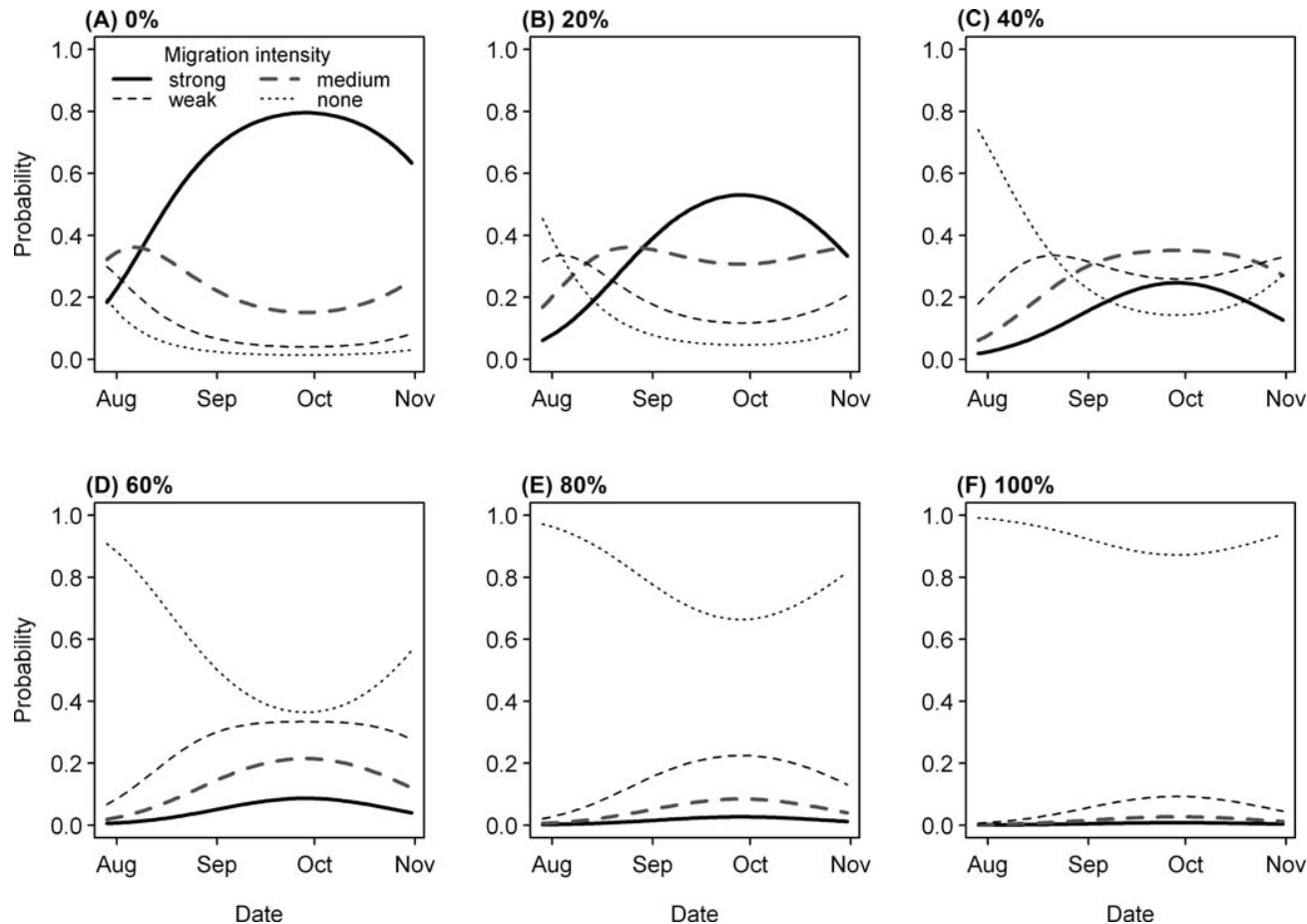

FIG. 3. Effects of date and precipitation coverage (A-F, in \%) on predicted probabilities for four migration intensities (legend in $\mathrm{A}$ ) based on the best model for Côte-Nord (Table 4A, model 10). Other variables were set at the following values: wind direction $=333^{\circ}$; wind speed $=1 \mathrm{~m} \mathrm{~s}^{-1}$; number of days since last adverse weather event $=1$.
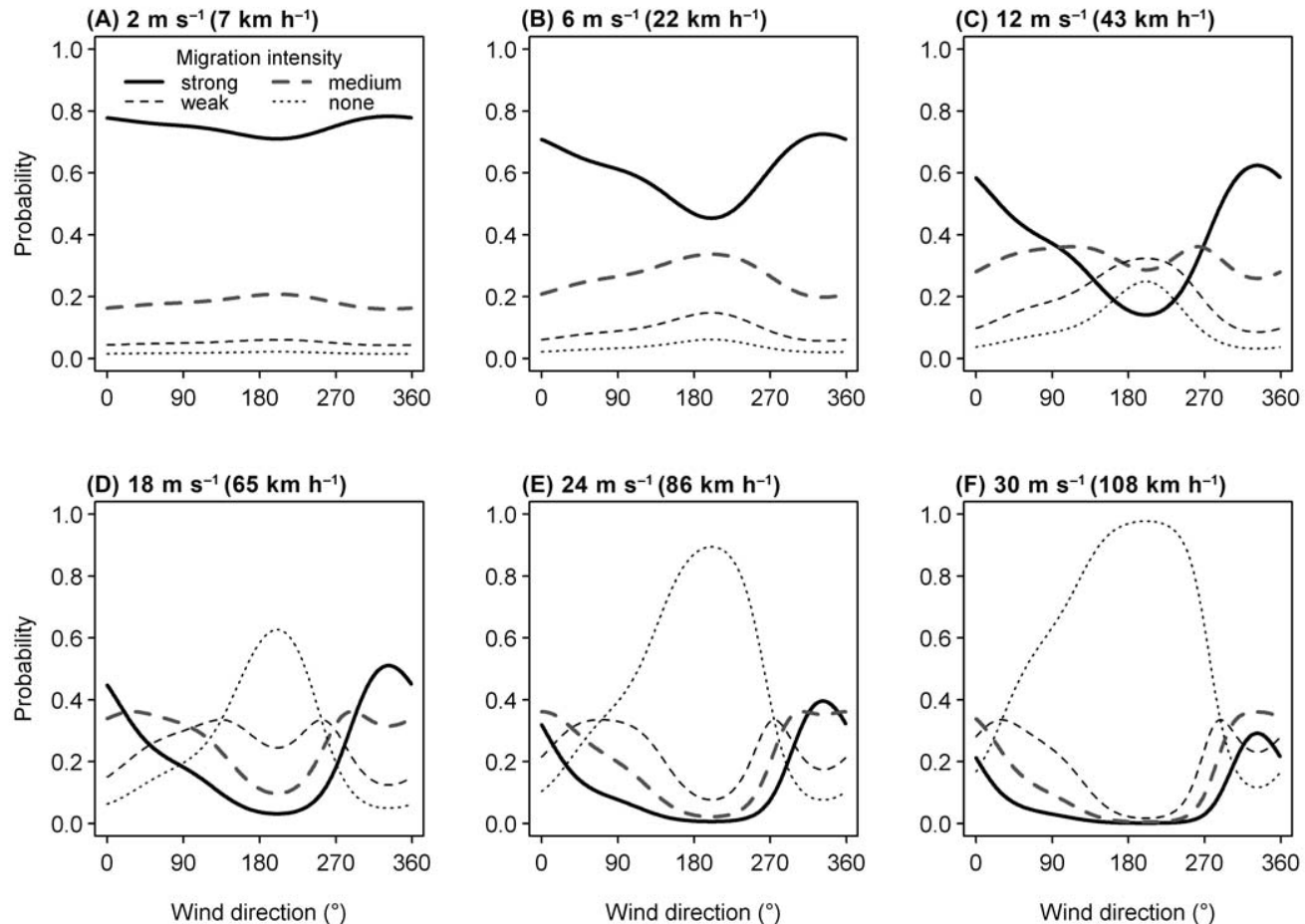

FIG. 4. Effects of wind direction in relation to wind speed on predicted probabilities of each category of migration intensity (legend in A) for Côte-Nord based on the best model (model 10; Table 4A). Other variables were set at the following values: date $=28$ September, precipitation coverage $=0 \%$, number of days since last adverse weather event $=1$. 

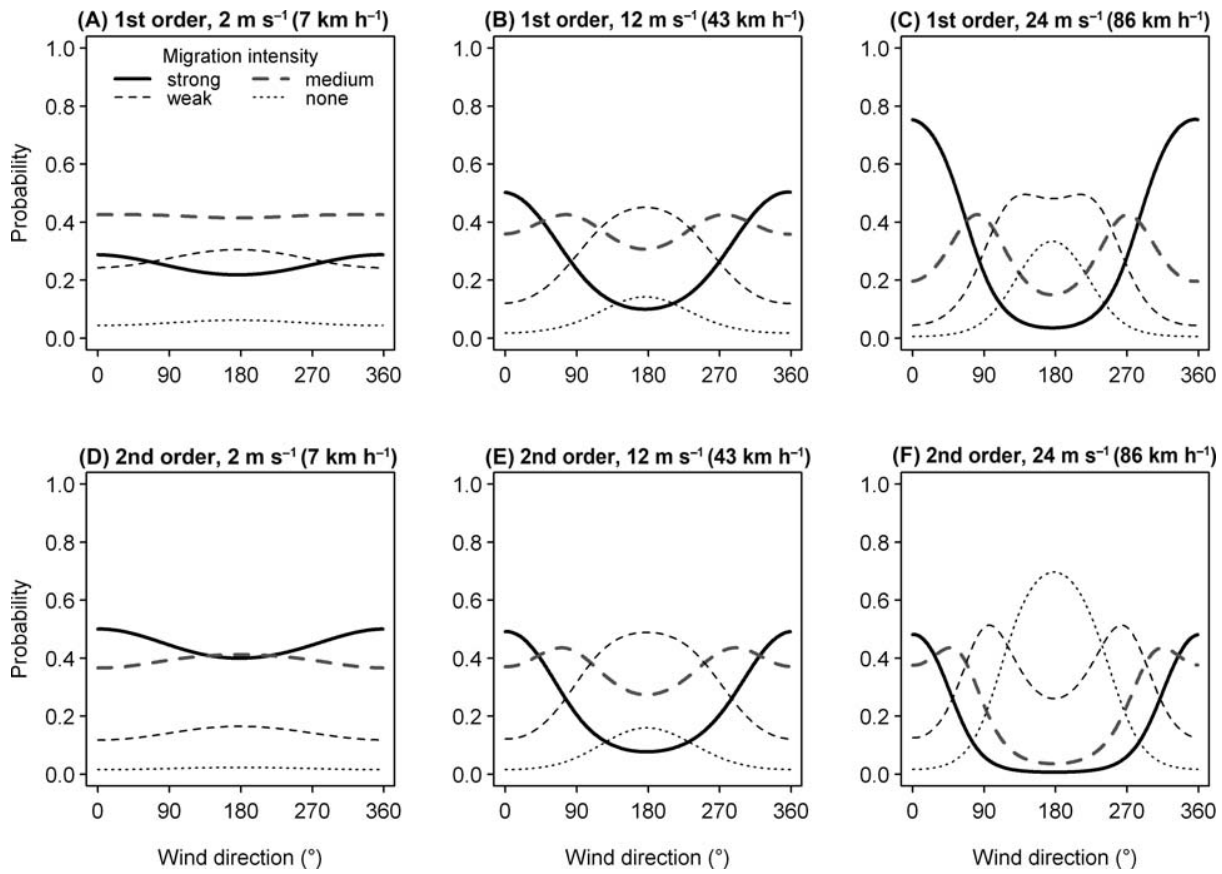

FIG. 5. Effects of wind direction in relation to wind speed on predicted probabilities of each category of migration intensity (legend in A) for Gaspésie, based on the two best models (see Table 4B): model 6 with the first-order wind function (A, B, C) and model 9 with the second-order wind function $(D, E, F)$. Other variables were set at the following values: date $=15$ September, precipitation coverage $=0 \%$.
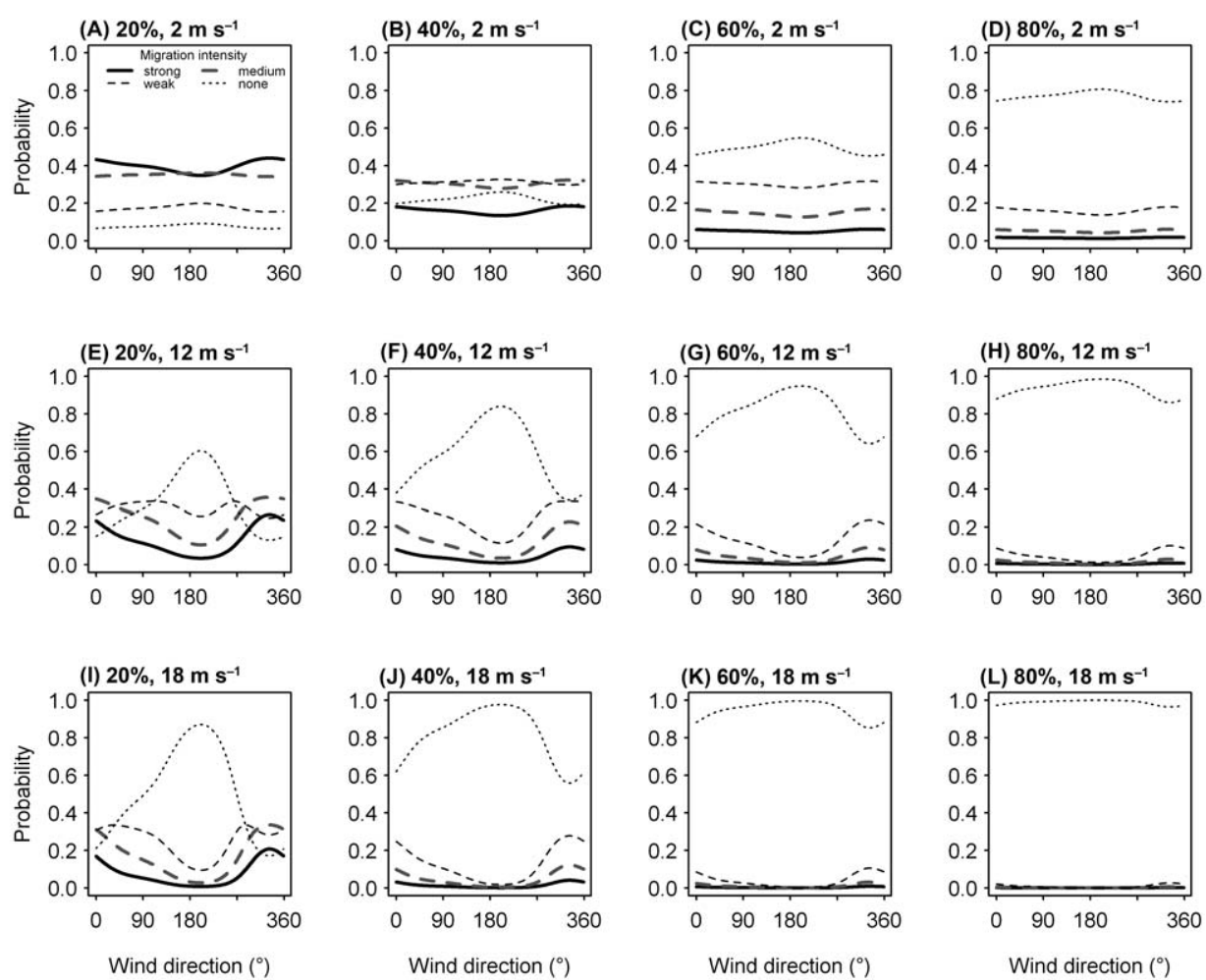

FIG. 6. Combined effects of precipitation coverage, wind speed, and wind direction on predicted probabilities of each category of migration intensity (legend in A) for Côte-Nord based on model 10 (Table 4A). Displays of $0 \%$ precipitation coverage are found in Figure 3. Other variables were set at the following values: date $=28$ September, number of days since last adverse weather event $=1$. 
conditions, but as the precipitation levels increased, moderate migration was more likely in late September or early October (Fig. 3). For Gaspésie (not illustrated), the pattern was similar, but the probability of strong migration peaked somewhat earlier in mid-September.

Precipitation.-Increased precipitation coverage led to a gradual suppression of migration intensity on Côte-Nord (Fig. 3) and Gaspésie (not illustrated). The highest probabilities of strong migration were observed between 0 and $20 \%$ precipitation coverage. At $30 \%$ coverage, the probability of strong migration was reduced to about half. Above $60-80 \%$ coverage, any level of migration was unlikely, although light migration still sometimes occurred during the timing of peak migration.

Wind.-We examined the effect of wind by standardizing the model for midseason with no precipitation. For Côte-Nord the probability of strong migration was very high when wind speed was low, regardless of wind direction (Fig. 4A). As the wind speed increased, the overall probability of strong migration decreased (Fig. 4B-F), whereas the influence of wind direction became more important. At $12 \mathrm{~km} \mathrm{~h}^{-1}$, winds directly from the south suppressed migration, whereas above $18 \mathrm{~km} \mathrm{~h}^{-1}$, any wind with a southerly component suppressed migration. There was also moderate east-west asymmetry, with greater suppression of migration with winds from the east than with winds from the west (Fig. 4D, E, F).

The patterns at Gaspésie were similar to those at Côte-Nord (Fig. 5), though details differed somewhat for the models using the first-order (Fig. 5A-C) or second-order (Fig. 5D-F) wind functions. Because these models were equally well supported in the model selection process, this reflects some of the uncertainty in our ability to predict migration. The suppression of strong migration by moderate $\left(12 \mathrm{~km} \mathrm{~h}^{-1}\right)$ or high northerly winds $\left(\geq 18 \mathrm{~km} \mathrm{~h}^{-1}\right)$ appeared to be rather weaker than on Côte-Nord. Otherwise, suppression of any migration activity by high southerly winds is weaker than on Côte-Nord and results were more symmetrical on the east-west axis.

Adverse weather events.-On Côte-Nord, the negative coefficient for days since an adverse weather event (Table 5) indicated that the probability of strong migration was higher immediately after an adverse weather event (as might be expected if the adverse weather had caused an accumulation of birds ready to migrate), and decreased subsequently. The slope of the relationship was in a similar direction for Gaspésie, but the effect was weaker and not statistically significant.

Cold fronts.-There was no evidence that the number of days since the last cold front was a significant predictor for migration intensity in either region (Tables 4 and 5).

Interactions between precipitation and wind.-On CôteNord (Fig. 6) and Gaspésie (not illustrated), migration was unlikely to be strong, with a combination of increasing precipitation coverage and wind speed, particularly for southerly winds. However, the winds had to be stronger and precipitation coverage more extensive in Gaspésie before the probability of no migration exceeded that of weak migration. Overall, as wind speed increased, a lower level of precipitation coverage was sufficient to suppress any migration activity (Fig. 6); when both increased, probabilities for no migration rose more rapidly in early autumn than during midseason (not illustrated).
Discussion

We found, as have many previous studies, that precipitation and wind both strongly influence the extent and intensity of bird migration. Extensive rain suppressed migration, although the extent of suppression interacted with date and wind. Light winds (regardless of direction) or stronger winds in a favorable direction (generally from the north) were associated with the heaviest migration. These general findings are similar to those of Richardson $(1978,1990)$, Zehnder et al. (2001), Erni et al. (2002), Schaub et al. (2004), and Van Belle et al. (2007) and make sense from an energetic perspective (Liechti 2006). Extensive precipitation may lower the ability of birds to orient, may increase drag and flight costs, or may affect thermoregulation (Schaub et al. 2004). Strong adverse winds can greatly reduce ground speed and can lead to drift. We found some evidence to support the notion that migration intensity may be highest during favorable conditions immediately after adverse weather, presumably due to a build-up of migrants ready to move (Baumgartner 1997 in Liechti and Bruderer 1998). We did not find support for the notion that cold fronts promote strong nocturnal migration. This may have been due to variable effects of cold fronts on wind direction. If a cold front passes an area well before it reaches the occlusion phase (i.e., when it overtakes a warm front), trailing winds are usually northwesterly or westerly, which promotes migration; however, if it passes close to the occlusion phase, wind directions shift closer to the southwest, which represses migration.

An innovative component of our analyses is the use of secondorder circular functions to model the migration intensity of birds in relation to wind, especially combined with the use of graphic displays that illustrate interactions among variables (e.g., Figs. 3-6). The second-order circular functions allow the modeling of asymmetric minima and maxima and more complex curvatures, and allowed us to better understand some of the observed differences in migration behavior between regions (see below). For example, despite their greater complexity, models with a second-order circular function were preferred by AIC for Côte-Nord (Table 4A), because they allowed us to model the asymmetry $\left(131^{\circ}\right.$ angle) between the most and least favorable winds under strong wind conditions that promoted high migration intensity (Fig. 4C-F). By contrast, for Gaspésie, the most and least favorable winds were almost symmetrically opposite $\left(177^{\circ}\right.$; Fig. 5 F); thus, the second-order wind function (model 9) and the first-order function (model 6) performed equally well (Table 4B). We suggest that biologists should consider using these higher-order functions whenever dealing with circular data when asymmetric effects may be involved.

We found several differences in migration behavior between birds migrating on opposite shores of the St. Lawrence. Although the weather conditions that prompted medium or strong migration were similar in both areas, on Côte-Nord the average migration directions on nights of medium to strong migration were in a west-southwest to south-southwest direction, whereas in Gaspésie they were predominantly south-southeast, a difference of $\leq 80^{\circ}$. In addition, on Côte-Nord the dominant flight directions were less variable among nights, with birds often flying with cross winds (high $\beta$ values), and there was no correlation between wind direction and migration direction. In Gaspésie, the birds tended to migrate downwind, on average, with lower $\beta$ values; migration direction was less consistent and varied with wind direction. 
One of the factors that may have driven the different migration behavior on the north and south sides of the St. Lawrence is a difference in migration routes for birds on the opposite sides of the estuary. Birds flying over Côte-Nord most likely originated from throughout central and northern Quebec and Labrador, whereas those over Gaspésie likely were a combination of locally originating birds and those from northern and eastern Quebec that crossed the estuary or the Gulf of St. Lawrence. Tracing orthodrome routes (i.e., the shortest route between two points on a sphere; Gudmundsson and Alerstam 1998) from the Côte-Nord along the mean flight direction during strong migration suggests that birds may fly along the St. Lawrence before following the western slope of the Appalachian ridge to the Gulf of Mexico. For these birds, crossing the estuary may represent an unwanted detour, with the St. Lawrence acting as a leading line along the intended route. In Gaspésie, the mean flight direction during strong migration would lead birds to the Atlantic coast, where most of them presumably change direction to follow the ocean coast, although some may subsequently fly over the ocean to the Caribbean or South America (e.g., Nisbet et al. 1995).

These results do not imply that there was no variation among individuals or among species within each region. It is important to note that our direction data were taken over areas where reflectivity from birds was the highest in each region on each night, representing the modal behavior. On Côte-Nord, even though the dominant direction for most birds was southwest along the coast, we also observed weaker movement of birds flying in a more southerly direction across the estuary. These birds would arrive in Gaspésie and then, presumably, have the migration pattern and behaviors described in this region. The St. Lawrence is not a very wide barrier and can be readily crossed in 1 to $1.5 \mathrm{~h}$ of flying (Gagnon et al. 2011). There are many technical challenges related to quantifying the relative numbers of birds flying in each direction that were beyond the scope of the present study. The different flight directions may result from variation in migration routes among species (Ball 1952) or age classes (Murray 1966; Ralph 1981; Thorup et al. 2003, 2007; Reilly and Reilly 2009). Alternatively, they may simply be contingent on the different geographic locations where the birds find themselves, or on local differences in wind patterns at the time of migration. Weather radar is not suitable for identifying species of birds and, thus, cannot be used to test these hypotheses.

The other major difference between regions was in the extent to which the birds compensated for wind drift. Compensation for wind drift occurs if birds fly at an angle to the wind, to correct for displacement in relation to their destination (Alerstam 1979). On Côte-Nord, the birds appeared to compensate very strongly to maintain their migration direction. On average, during strong migration, the birds were flying at $\sim 80^{\circ}$ to the wind (Table $3 \mathrm{~A}$ ), with the wind coming predominantly from the right side (i.e., northwest when the birds were flying to the southwest). The observed $\beta$ during medium migrations on Côte-Nord $\left(144^{\circ}\right)$ suggests that there may even have been some overcompensation (i.e., shifting too much into the wind of the average track direction; Alerstam 1979). This strong compensation suggests that the birds avoided crossing the estuary, given that mean flight directions corresponded roughly to the axis of the north shore (Table 2A). Compensation near large rivers or distinct topographical features along preferred migratory directions to avoid wind displacement have been reported in others areas (Alerstam and Pettersson 1977, Bingman et al. 1982, Åkesson 1993, Bruderer and Liechti 1998, Zehnder et al. 2001).

During strong migration in Gaspésie, the observed $\beta$ value $\left(55^{\circ}\right.$, predominantly on the right side) and the lack of correlation between wind and flight directions suggest some level of compensation, although when the wind was stronger, the wind direction with the highest probability of migration was in essentially the same direction as the migration path, such that compensation would not be required (Table 2B; Fig. 5). For medium and weak migrations in Gaspésie, the data suggest drift, with flight direction correlated with wind, including some downwind flights toward seasonally inappropriate eastward directions. "Reverse migration" in the United States has often been associated with downwind flights in a seasonally inappropriate direction (Richardson 1990). Partial drift may also occur, if birds make some corrections without fully compensating for wind displacement, whereas "drift" refers to birds flying without correcting for wind (Alerstam 1979). Some of the observed "drift" may also have been pseudo-drift-that is, the correlation between wind and the average direction of bird migration that arises as a consequence of selective departures under different wind conditions of migrants with different preferred track directions and destinations (Alerstam and Hedenström 1998). Because we do not know the species and their migratory goals, this cannot be fully discriminated, though it is likely that most nocturnal migrants in these regions had destinations roughly to the south.

Given bird migration theory, compensation and overcompensation should occur when wind velocity is low and consistently from a single direction, whereas drift and partial drift should be expected when the wind speed and direction vary among nights or at higher wind velocities (Alerstam 1979, Alerstam and Hedenström 1998). The ability of birds to compensate for wind drift depends on wind speed (Alerstam 1978). Thus, stronger side winds should limit the ability of birds to compensate on Côte-Nord and may involve significant risks of drifting toward Gaspésie. This may explain why the modeled relationships with wind suggested that high wind speeds suppressed strong migration activity on Côte-Nord more than they did in Gaspésie. Our weather data (Table 1) show that in fall 2003, wind velocities were mainly $<12 \mathrm{~m} \mathrm{~s}^{-1}$ (the average air speed of passerines) in both regions, which suggests that birds should be able to compensate, at least to some degree, most of the time.

The more consistent compensation and the concentration of flight directions along Côte-Nord suggest that flight behavior in relation to wind may be influenced by the availability of geographic landmarks. Liechti (2006) suggested that birds could more accurately estimate wind displacement, as well as their speed and fuel consumption, by using landmarks. Birds have a large lateral view and preferentially fixate objects in their lateral view (Güntürkün 2000), which permits them to estimate the relative motion of distant landmarks without the need to inspect the motion of a single landmark (Liechti 2006). On the south coast, the more scattered flight directions and drift-related flight suggest that their flight behavior may have been governed by navigational factors other than geographic cues, which limited their ability to compensate.

In conclusion, the results of our study demonstrate the enormous, largely unrealized potential of weather radars to develop predictive models of bird migration in North America and to further our understanding of geographic variation in migration behavior. Only a limited number of studies have previously used 
weather radar to look at large-scale migration patterns in relation to geographic features (e.g., Gauthreaux and Belser 1998, Dieh et al. 2003, Gauthreaux et al. 2003), often for only a few nights. Our analyses over a complete season enabled us to develop models that quantified how migration changed with weather, and also to detect major differences in migration patterns on each side of a major geographic feature (the St. Lawrence River). The broad geographic coverage of weather radars, combined with ongoing improvements to software for processing the large volumes of data they generate, provide many new opportunities to undertake research to understand migration patterns in North America.

\section{ACKNOWLEDGMENTS}

We thank J. E. Black of Brock University and N. Donaldson of the Meteorological Service of Canada, Environment Canada, for practical advice regarding Canadian weather radar; R. Verreault for advice on second-order functions; and D. Haboudane of Université du Québec à Chicoutimi for a loan of materials. RAPID software was provided by the J.S. Marshall Radar Laboratory of McGill University and the radar data were provided by the Meteorological Service of Canada of the Québec region, Environment Canada. For the data we used for wind components, see weather.uwyo.edu/ upperair/naconf.html, and for surface analysis chart see meteocentre.com/archive/. We appreciated constructive criticisms of previous versions of the manuscript made by two anonymous reviewers. This study was financially supported by the Consortium de recherche sur la forêt boréale commerciale, Université de Sherbrooke, Canadian Wildlife Service-Québec, Natural Resources Canada, and the National Wildlife Research Centre (Ottawa). Finally, we thank B. Parsons for linguistic revision.

\section{Literature Cited}

Agresti, A. 1996. An Introduction to Categorical Data Analysis Wiley, New York.

ÅKESSON, S. 1993. Coastal migration and wind drift compensation in nocturnal passerine migrants. Ornis Scandinavica 24:87-94.

ÅKesson, S., AND A. Hedenström. 2000. Wind selectivity of migratory flight departures in birds. Behavioral Ecology and Sociobiology 47:140-144.

Alerstam, T. 1978. A graphical illustration of pseudo-drift. Oikos 30:409-412.

Alerstam, T. 1979. Optimal use of wind by migrating birds: Combined drift and overcompensation. Journal of Theoretical Biology 79:341-353.

Alerstam, T., And A. Hedenström. 1998. The development of bird migration theory. Journal of Avian Biology 29:343-369.

Alerstam, T., AND S. G. Pettersson. 1977. Why do migrating birds fly along coastlines? Journal of Theoretical Biology 65:699-712.

ANDERSON-CoOK, C. M. 2000. A second-order model for cylindrical data. Journal of Statistical Computation and Simulation 66:51-65.

Ball, S. C. 1952. Fall bird migration on the Gaspé Peninsula. Peabody Museum of Natural History, Yale University, New Haven, Connecticut.

BatsChelet, E. 1981. Circular Statistics in Biology. Academic Press, London.
BAUmgarTner, M. 1997. Wetterabhängigkeit des nächtlichen Volgelzuges im Herbts über Süddeutschland. Ph.D. dissertation, Schweizerische Vogelwarte Sempach, Switzerland.

Bingman, V. P., K. P. Able, And P. Kerlinger. 1982. Wind drift, compensation, and the use of landmarks by nocturnal migrants. Animal Behaviour 30:49-53.

BRUDERER, B., AND A. BOLDT. 2001. Flight characteristics of birds: I. Radar measurements of speeds. Ibis 143:178-204.

BRUDERER, B., AND F. LieCHTI. 1998. Flight behaviour of nocturnally migrating birds in coastal areas-Crossing or coasting. Journal of Avian Biology 29:499-507.

Burnham, K. P., And D. R. Anderson. 2002. Model Selection and Multimodel Inference: A Practical Information-Theoretic Approach, 2nd ed. Springer-Verlag, New York.

CARpenter, J., AND J. Bithell. 2000. Bootstrap confidence intervals: When, which, what? A practical guide for medical statisticians. Statistics in Medicine 19:1141-1164.

Davison, A. C., AND D. V. Hinkley. 1997. Bootstrap Methods and Their Applications. Cambridge University Press, Cambridge, United Kingdom.

DieHL, R. H., R. P. LARKIN, AND J. E. BlaCk. 2003. Radar observations of bird migration over the Great Lakes. Auk 120:278-290.

EAST wOOD, E. 1967. Radar Ornithology. Methuen, London.

Erni, B., F. Liechti, L. G. Underhill, and B. Bruderer. 2002. Wind and rain govern the intensity of nocturnal bird migration in central Europe-A log-linear regression analysis. Ardea 90:155-166.

Fisher, N. I. 1993. Statistical Analysis of Circular Data. Cambridge University Press, Cambridge, United Kingdom.

FisHer, N., AND LEE, A. 1983. A correlation coefficient for circular data. Biometrika 70:327-332.

Fox, J. 2003. Effect displays in R for generalised linear models. Journal of Statistical Software 8:1-27.

Gagnon, F., M. Bélisle, J. Ibarzabal, P. Vaillancourt, and J.-P. L. SAVARD. 2010. A comparison between nocturnal aural counts of passerines and radar reflectivity from a Canadian weather surveillance radar. Auk 127:119-128.

Gagnon, F., I. Ibarzabal, M. BÉlisle, J.-P. L. SaVard, and P. VAILlANCOURT. 2011. Autumnal patterns of nocturnal passerine migration in the St. Lawrence estuary region, Quebec, Canada: A weather radar study. Canadian Journal of Zoology 89:31-46.

Gauthreaux, S. A., JR., And C. G. Belser. 1998. Displays of bird movements on the WSR-88D: Patterns and quantification. Weather and Forecasting 13:453-464.

Gauthreaux, S. A., Jr., C. G. Belser, and D. Van Blaricom. 2003. Using a network of WSR-88D weather surveillance radars to define patterns of bird migration at large spatial scales. Pages 335-346 in Avian Migration (P. Berthold, E. Gwinner, and E. Sonnenschein, Eds.). Springer-Verlag, Berlin.

Gauthreaux, S. A., Jr., J. W. Livingston, and C. G. Belser. 2008. Detection and discrimination of fauna in the aerosphere using Doppler weather surveillance radar. Integrative and Comparative Biology 48:12-23.

Gudmundsson, G. A., AND T. Alerstam. 1998. Optimal map projections for analysing long-distance migration routes. Journal of Avian Biology 29:597-605.

GÜNTÜRKÜN, O. 2000. Sensory physiology: Vision. Pages 1-14 in Sturkie's Avian Physiology, 5th ed. (G. C. Whittow, Ed.). Academic Press, San Diego, California. 
Jammalamadaka, S. R., and A. SenGupta. 2001. Topics in Circular Statistics. World Scientific Publishing, Singapore.

Joe, P., D. Hudak, C. Crozier, J. Scott, and M. Falla. 1998. Signal processing and digital IF on the Canadian Doppler Radar network. Pages 1-13 in Cost 75 Final International Seminar on Advanced Weather Radar Systems, Locarno, Switzerland.

JoE, P., AND S. LAPCZAK. 2002. Evolution of the Canadian operational radar network. Pages 370-382 in Proceeding of the 2nd European Conference on Radar in Meteorology and Hydrology (ERAD), Delft, The Netherlands.

Koistinen, J. 2000. Bird migration patterns on weather radars. Physics and Chemistry of the Earth B 25:1185-1193.

LARKIN, R. P. 1991. Flight speeds observed with radar, a correction Slow "birds" are insects. Behavioral Ecology and Sociobiology 29:221-224.

LIECHTI, F. 2006. Birds: Blowin' by the wind? Journal of Ornithology 147:202-211

LieChti, F., AND B. BRUdERER. 1998. The relevance of wind for optimal migration theory. Journal of Avian Biology 29:561-568.

LOWERY, G. H., AND R. J. NEwMAN. 1966. A continent-wide view of bird migration on four nights in October. Auk 83:547-586.

MurRay, B. G., JR. 1966. Migration of age and sex classes of passerines on the Atlantic coast in autumn. Auk 83:352-360.

Nisbet, I. C. T., D. B. McNair, W. Post, and T. C. Williams. 1995. Transoceanic migration of the Blackpoll Warbler: Summary of scientific evidence and response to criticisms. Journal of Field Ornithology 66:612-622.

R Development Core Team. 2006. R: A Language and Environment for Statistical Computing. R Foundation for Statistical Computing, Vienna.

RALPH, C. J. 1981. Age ratios and their possible use in determining autumn routes of passerine migrants. Wildlife Society Bulletin 93:164-188.

ReILly, J. R., AND R. J. ReILly. 2009. Bet-hedging and the orientation of juvenile passerines in fall migration. Journal of Animal Ecology 78:990-1001.
RiCHARDSON, W. J. 1972. Autumn migration and weather in eastern Canada. American Birds 26:10-17.

RichaRdSON, W. J. 1978. Timing and amount of bird migration in relation to weather: A review. Oikos 30:224-272.

RICHARDSON, W. J. 1990. Wind and orientation of migrating birds: A review. Experientia 46:416-425.

RiNeHART, R. E. 1997. Radar for Meteorologists, 3rd ed. Rinehart, Grand Forks, North Dakota

Schaub, M., F. Liechti, AND L. Jenni. 2004. Departure of migrating European Robins, Erithacus rubecula, from a stopover site in relation to wind and rain. Animal Behaviour 67:229-237.

Thorup, K., T. Alerstam, M. Hake, and N. Kjellén. 2003. Bird orientation: Compensation for wind drift in migrating raptors is age dependent. Proceedings of the Royal Society of London, Series B (Supplement) 270:S8-S11.

Thorup, K., I.-A. Bisson, M. S. Bowlin, R. A. Holland, J. C. Wingfield, M. Ramenofsky, AND M. Wikelski. 2007. Evidence for a navigational map stretching across the continental U.S. in a migratory songbird. Proceedings of the National Academy of Sciences USA 104:18115-18119.

Van Belle, J., J. Shamoun-Baranes, E. Van Loon, and W. Bouten. 2007. An operational model predicting autumn bird migration intensities for flight safety. Journal of Applied Ecology 44:864-874.

Weber, T. P., B. J. ENs, AND A. I. Houston. 1998. Optimal avian migration: A dynamic model of fuel stores and site use. Evolutionary Ecology 12:377-401.

ZAR, J. H. 1996. Biostatistical Analysis, 3rd ed. Prentice Hall, Upper Saddle River, New Jersey.

Zehnder, S., S. Åkesson, F. Liechti, and B. Bruderer. 2001. Nocturnal autumn bird migration at Falsterbo, south Sweden. Journal of Avian Biology 32:239-248.

Associate Editor: C. M. Rogers 